\title{
Changes in frailty status after cardiac surgery. A prospective cohort study.
}

\author{
Javier Miguelena ${ }^{1}$, Jose Lopez-Menendez ${ }^{2}$, Pablo Prada ${ }^{3}$, Miren Martín García $^{4}$, Carlota \\ Vigil-Escalera $^{5}$, Magali Gonzalez-Colaço ${ }^{3}$, Rafael Muñoz Pérez ${ }^{4}$, and Jorge \\ Rodriguez-Roda Stuart ${ }^{4}$ \\ ${ }^{1}$ Hospital Ramon y Cajal \\ ${ }^{2}$ Hospital Universitario Ramon y Cajal \\ ${ }^{3}$ Hospital Universitario de Canarias \\ ${ }^{4}$ Ramon y Cajal Hospital \\ ${ }^{5}$ Hospital Universitario Central de Asturias
}

April 30, 2021

\begin{abstract}
Background During the last years, the concept of frailty has become increasingly familiar in many surgical specialties, including cardiac surgery. One of the main characteristics of frailty is its potentially reversible nature. With the aim of reducing the incidence of complications after surgery, efforts are being made to preoperatively decrease the level of frailty, however, the effect that the surgery itself may have in the postoperative frailty status is still unknown. Methods A prospective cohort of 137 patients aged 70 or more undergoing cardiac surgery with the use of cardiopulmonary bypass were recruited at three university-affiliated hospitals in Spain. Frailty status was assessed preoperatively and six months after surgery using two different validated frailty measurements: The Fried frailty scale and the Clinical Frailty Scale. We analyzed the changes in these frailty scores and the transitions between frailty status after surgery. Results Prevalence of frailty was $27.5 \%$ with the Fried Frailty Scale and $11 \%$ with the Clinical Frailty Scale. Even though frail patients presented a higher incidence of postoperative major complications than their robust counterparts, up to $50 \%$ of frail patients improved their frailty status after surgery. The distribution of frailty groups at baseline and six months after surgery changed significantly, decreasing the overall burden of frailty after surgery. Besides, robust patients showed a slightly worsening of their previous frailty scores. Conclusions Frailty is a multifactorial and dynamic condition that can be significantly reduced after cardiac surgery, suggesting that cardiac pathology is an important contributor to the preoperative patient's frailty status.
\end{abstract}

\section{CHANGES IN FRAILTY STATUS AFTER CARDIAC SURGERY. A PROSPECTIVE CO- HORT STUDY}

Javier Miguelena-Hycka MD, $\mathrm{PhD}^{1}$; Jose Lopez-Menendez $\mathrm{MD}, \mathrm{PhD}^{1}$; Pablo-Cesar Prada $\mathrm{MD}^{2}$, Miren Martin García $\mathrm{MD}^{1}$; Carlota Vigil-Escalera, $\mathrm{MD}^{3}$, Magali Gonzalez-Colaço Harmand, $\mathrm{MD}, \mathrm{PhD}^{4}$, Rafael Muñoz Pérez, $\mathrm{MD}^{1}$; Jorge Rodriguez-Roda $\mathrm{MD}^{1}$

1 Department of Cardiac Surgery, Ramon y Cajal University Hospital, Madrid, Spain.

2 Department of Cardiac Surgery, University Hospital of Canary Islands, Tenerife, Spain.

3 Department of Cardiac Surgery, Asturias Central University Hospital, Oviedo, Spain.

4 Clinical Trials and Clinical Research Unit, University Hospital of Canary Islands, Spain.

Key Words: Frailty, Outcomes, Cardiac Surgery. 


\section{Word count: 4369}

\section{Corresponding author:}

Javier Miguelena (ORCID ID: https://orcid.org/0000-0002-2006-3733)

Cardiac Surgery Department, Ramon y Cajal Hospital.

Ctra. De Colmenar Viejo, km. 9,100, 28034 Madrid. Spain.

Phone: +34 913368049

e-mail:jmiguelena@hotmail.com

This manuscript has not been previously published in whole or in part in any form, including being published in another language besides English, and is not under consideration in the same or substantially similar form in any other peer-reviewed media. All authors listed have contributed sufficiently to the project to be included as authors. All the authors have read and approved the final manuscript, all authors have read and approve of the data being presented in the manuscript. The data that support the findings of this study are available from the corresponding author upon reasonable request. To the best of our knowledge, no conflict of interest, financial or other, exists.

\section{ABSTRACT}

\section{Background}

During the last years, the concept of frailty has become increasingly familiar in many surgical specialties, including cardiac surgery. One of the main characteristics of frailty is its potentially reversible nature. With the aim of reducing the incidence of complications after surgery, efforts are being made to preoperatively decrease the level of frailty, however, the effect that the surgery itself may have in the postoperative frailty status is still unknown.

\section{Methods}

A prospective cohort of 137 patients aged 70 or more undergoing cardiac surgery with the use of cardiopulmonary bypass were recruited at three university-affiliated hospitals in Spain. Frailty status was assessed preoperatively and six months after surgery using two different validated frailty measurements: The Fried frailty scale and the Clinical Frailty Scale. We analyzed the changes in these frailty scores and the transitions between frailty status after surgery.

\section{Results}

Prevalence of frailty was $27.5 \%$ with the Fried Frailty Scale and $11 \%$ with the Clinical Frailty Scale. Even though frail patients presented a higher incidence of postoperative major complications than their robust counterparts, up to $50 \%$ of frail patients improved their frailty status after surgery. The distribution of frailty groups at baseline and six months after surgery changed significantly, decreasing the overall burden of frailty after surgery. Besides, robust patients showed a slightly worsening of their previous frailty scores.

\section{Conclusions}

Frailty is a multifactorial and dynamic condition that can be significantly reduced after cardiac surgery, suggesting that cardiac pathology is an important contributor to the preoperative patient's frailty status.

\section{INTRODUCTION}

Frailty is currently considered as a multicausal medical syndrome that is characterized by a diminished strength and endurance. Frailty also implies a reduced physiological reserve, that increases an individual's vulnerability to develop dependency and/or death after different stress situations (1). 
This identification of frailty as an increased vulnerability of adverse health outcomes in community-dwelling adults (2-4) led to the characterization of frailty as an independent risk factor for mortality and morbidity in different medical and surgical scenarios(5-7), including cardiac surgery (8-12).

On the one hand, many studies focused on the utility of frailty to predict adverse events after a surgical procedure (9-12). On the other hand, more recent research has focused on the reversible nature of frailty. In this way, it is generally considered that a decrease in the preoperative frailty status will presumably reduce the incidence of postoperative complications. Therefore, efforts are being made to implement specific physical exercises and pharmacological treatments with the aim to reduce the level of frailty during the preoperative period $(13,14)$. This set of preoperative measures has come to be calledprehabilitation (15-18).

Based also on this dynamic nature of frailty, it would also be interesting to investigate the possibility of changes in frailty status after cardiac surgery. A postoperative improvement in frailty would be expected to the extent that the cardiac pathology was contributing to it. We have recently published that frail patients can improve their quality of life after surgery (19), but postoperative changes in frailty status have not been analyzed. Besides, as a result of the surgical aggression, a postoperative deterioration of the frailty status could also be hypothesized, especially in vulnerable and frail patients. However, there is scarce evidence on this issue and very few studies have addressed it $(20,21)$.

Therefore, the objective of this study was the analysis of the changes of the frailty status that occur six months after a major cardiac surgery with the use of cardiopulmonary bypass.

\section{METHODS}

\section{Patient population and study design}

Between April 2015 and December 2016, a cohort of patients aged 70 or more undergoing elective cardiac surgery with cardiopulmonary bypass were recruited at three university-affiliated hospital of three different regions of Spain (Madrid, Asturias, and Canary Islands).

Using this cohort of patients, we analyzed the changes in the level of frailty after cardiac surgery with respect to the preoperative ones.

The Institutional Research Ethics Committees at each of the participating hospitals approved the implementation of this study, and every patient provided signed informed consent.

Exclusion criteria were urgent or emergent surgery, off-pump operations, and the absence of the necessary capacity to understand and collaborate in the study. Patients with neurological or physical impairment that could bias the results of the frailty assessment were also excluded.

Frailty was assessed at the time of the hospital admission before the operation, and six months after surgery, using the same frailty assessment tools.

Medical records were used to extract demographic, clinical and surgically related variables.

\section{Frailty assessment}

Frailty status was assessed using two validated and widely used scales: The Fried phenotypical frailty scale (2) and the Clinical Frailty Scale (CFS) (22).

\section{Fried frailty scale}

This scale works as a scoring system that assigns one point for the presence of each of the following 5 phenotypical manifestations that are commonly found in frail individuals: shrinking (self-report of unintentional weight loss of $>4.5 \mathrm{~kg}$ in the past year), self-reported exhaustion, weakness (measured with grip strength and standardized by sex and body mass index), slow walking speed (measured as time to walk $4.6 \mathrm{~m}$. at usual pace and standardized by sex and height), and low physical activity (using as cut-off value the consumption of $<383 \mathrm{Kcal}$ per week for men and $<270 \mathrm{Kcal}$ per week for women). According to the total score obtained, the individuals are classified as robust (0 points), pre-frail (1-2 points) and frail (3-5 points). 


\section{Clinical Frailty Scale}

This scale was developed using data from the Canadian Study of Health and Aging in Canada. It is based on the interviewer's clinical judgment and constitutes a more subjective assessment of frailty.

The scale consists of 9 ordinal levels, ranging between 1 "very fit" and 9 "terminally ill". In order to facilitate the interviewer in classifying patients, the scale shows a short-written description and a figure representing a theoretical silhouette of an individual that would fit in each level.

We considered frail patients those in levels 5-8. Levels 3-4 were considered as pre-frail and levels 1-2 as robust.

\section{Other variables}

We collected basal and demographical variables for each patient by direct interview or reviewing medical records. The Charlson index was used to assess comorbidities (23). Clinical and surgical-related variables were also collected.

Operative risk was calculated using the European System for Cardiac Operative Risk Evaluation (EuroSCORE) I and II $(24,25)$. Health-related quality of life (HRQoL) was assessed using the EuroQOL 5D5L questionnaire (26).

\section{Statistical analysis}

The patients who died, or did not complete the follow-up period, were excluded from the study as the analysis of the changes in frailty status after surgery was not possible.

Continuous variables are expressed as median and interquartile interval (IQI) or mean and standard deviation (SD), depending on the normality of their distribution as assessed with Shapiro-Wilk normality test. Categorical data are presented as counts and percentages.

Differences among the three ordinal levels of frailty were analyzed considering the presence of a linear trend between categories. The Mantel Haenszel linear trend test was used for categorical variables, and linear regression models were employed for quantitative ones. Concordance between frailty scales was assessed with the Kappa index.

Chi-square test was used to compare the distribution of frailty groups before and after surgery. Changes in the proportion of patients who score a point in each of the components of the frailty phenotype was analyzed using the Mc Nemar's test for paired proportions.

All the statistical analysis and graphics were performed using Stata/IC 15.0 Software (Statacorp LP, College Station, TX). A significance level $\mathrm{p}<0.05$ was considered as statistically significative.

\section{RESULTS}

\section{Study Population}

During the study period, 500 patients aged 70 or more were referred for elective surgery in the three participating hospitals. 143 of these patients were initially recruited for the study, but 6 of them were excluded from the analysis because they withdraw the informed consent, or the data was incomplete.

Finally, 137 patients were included in the study and 109 of them completed the 6-month follow-up period. 12 patients $(8.8 \%)$ died within the study period, and 16 patients were lost during follow-up(figure 1 ). 


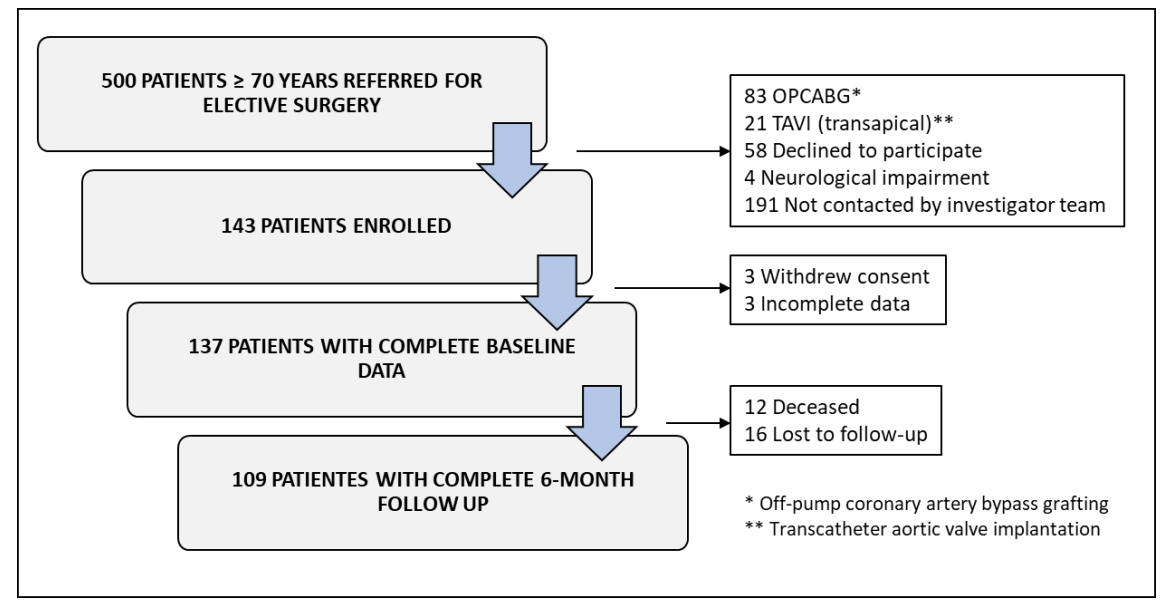

Figure 1. Enrollment flowchart.

The mean age was 78.1 years (SD 4,1, range $70.1-88.1$ ). $47.7 \%$ of patients were female. The most frequent surgery performed was isolated valve surgery $(78.9 \%), 11 \%$ of patients underwent combined valve and coronary surgery, whereas isolated coronary artery bypass surgery (CABG) was performed in $6.4 \%$ of patients. Basal characteristiscs of the patients are shown in table 1 .

Table 1. Basal characteristics of the patients

\section{$\mathbf{N}$}

Age, yrs

Female

BMI $(\mathrm{kg} / \mathrm{m} 2)^{1}$

Comorbidities

$\mathrm{HBP}^{2}$

Dyslipidemia

Diabetes $^{3}$

Atrial fibrillation ${ }^{4}$

COPD $^{5}$

Cerebrovascular disease ${ }^{6}$

Previous cardiac surgery

Charlson index

NYHA functional class III-IV ${ }^{7}$

Laboratory values

Hemoglobin (mg/dl)

Proteins (mg/dl)

Creatinin (mg/dl)

Preoperative risk

EuroSCORE I

EuroSCORE II

Surgical procedure

$\mathrm{CABG}^{8}$

Valvular

CABG + Valvular

Other surgeries

CPB time (min) 
$\mathbf{N}$

Cross clamp time

Fried Frailty Scale

Frail

Pre-frail

Robust

CFS $^{9}$

Very fit

Fit

Managing well

Vulnerable

Mildly frail

Moderately frail

CFS (categorized)

Frail

Pre-frail

Robust

Values are expressed as mean $\pm \mathrm{SD}$, median (IQI) or $\mathrm{n}(\%)$. 1.BMI: Body mass index. 2.HBP: High blood pressure. 3.Patie

\section{Prevalence and clinical profile of frailty}

The prevalence of frail patients varied between $27.5 \%$ with the Fried scale and $11.0 \%$ with the CFS. Prefrail and robust patients were $48.6 \%$ and $23.9 \%$ with the Fried scale and $73.4 \%$ and $15.6 \%$ with the CFS respectively.

The concordance between both scales when classifying individuals as "frail" or "non-frail", assessed with the kappa index, was only moderate (kappa index 0.52).

As the frailty status increased, there was a significative linear trend towards being female and older age, worse functional status, lower hemoglobin and worse quality of life.

Figure 2 summarizes, for the basal characteristics of the patients, the presence or not of significative linear trend among the three ordinal levels of frailty. 


\begin{tabular}{|c|c|c|c|}
\hline & FRIED & $\mathrm{CFS}^{\circ}$ & \\
\hline \multicolumn{4}{|l|}{ Older age } \\
\hline \multicolumn{4}{|l|}{ Female } \\
\hline $\mathrm{BMI}^{1}$ & & & \multirow{2}{*}{$\begin{array}{l}\text { Lineal trend significance } \\
(p<0,05)\end{array}$} \\
\hline High $\mathrm{BP}^{2}$ & & & \\
\hline Dyslipidemia & & & \multirow{2}{*}{$\begin{array}{l}\text { Lineal trend significance } \\
(0,05>p<0,1)\end{array}$} \\
\hline Diabetes & & & \\
\hline Atrial fibrillation ${ }^{3}$ & & & No lineal trend \\
\hline \multicolumn{4}{|l|}{$\mathrm{COPD}^{4}$} \\
\hline$C D^{5}$ & & & \multirow{12}{*}{$\begin{array}{l}{ }^{*} \text { Clinical Frailty Scale } \\
\text { (1) BMI: body mass index (kg/m2); (2) } \\
\text { BP: blood pressure; ; (3) Paroxystic, } \\
\text { persistent or permanent atrial } \\
\text { fibrillation; (4) COPD: chronic obstructive } \\
\text { pulmonary disease; (5) CVD: } \\
\text { cerebrovascular disease; (6) NYHA: New } \\
\text { York Health Association functional class; } \\
\text { (7)Katz index of Activities of Daily Living; } \\
\text { (8) Lawton index of Instrumental } \\
\text { Activities of Daily Living; (9) Health- } \\
\text { related Quality of Life index (EQ-5D); } \\
\text { (10) Health-related Quality of Life Visual } \\
\text { Analogue Scale (EQ-5D) }\end{array}$} \\
\hline Charlson index & & & \\
\hline NYHA III-IV & & & \\
\hline $\mathrm{ADL}(\text { Katz })^{7}$ & & & \\
\hline IADL (Lawton) ${ }^{8}$ & & & \\
\hline Anemia & & & \\
\hline Low plasmatic proteins & & & \\
\hline Creatinine & & & \\
\hline EuroSCORE I & & & \\
\hline EuroSCORE II & & & \\
\hline HRQoL (index) ${ }^{9}$ & & & \\
\hline HRQoL (VAS) ${ }^{10}$ & & & \\
\hline
\end{tabular}

Figure 2. Linear trend among the three ordinal levels of frailty

\section{Changes in frailty status 6-month after surgery}

Changes in Frailty prevalence

With both the Fried scale and the CFS, the prevalence of the different frailty groups significantly changed 6 months after surgery with respect to their baseline distribution $(\mathrm{p}<0.01)$.

Figure 3 shows the differences in the prevalence of frailty, before and 6 months after surgery. The direction of these changes was towards a decrease in the overall burden of frailty in the entire cohort of patients. In this way, the patients classified as frail with the Fried scale went from $27.5 \%$ in the preoperative period to $17 \%$ after 6 months of follow-up. On the CFS scale, the most remarkable change occurred in vulnerable patients, who decreased from 39.5 to $22 \%$. 


\section{Changes in frailty prevalence \\ Preoperative and 6-month postop.}
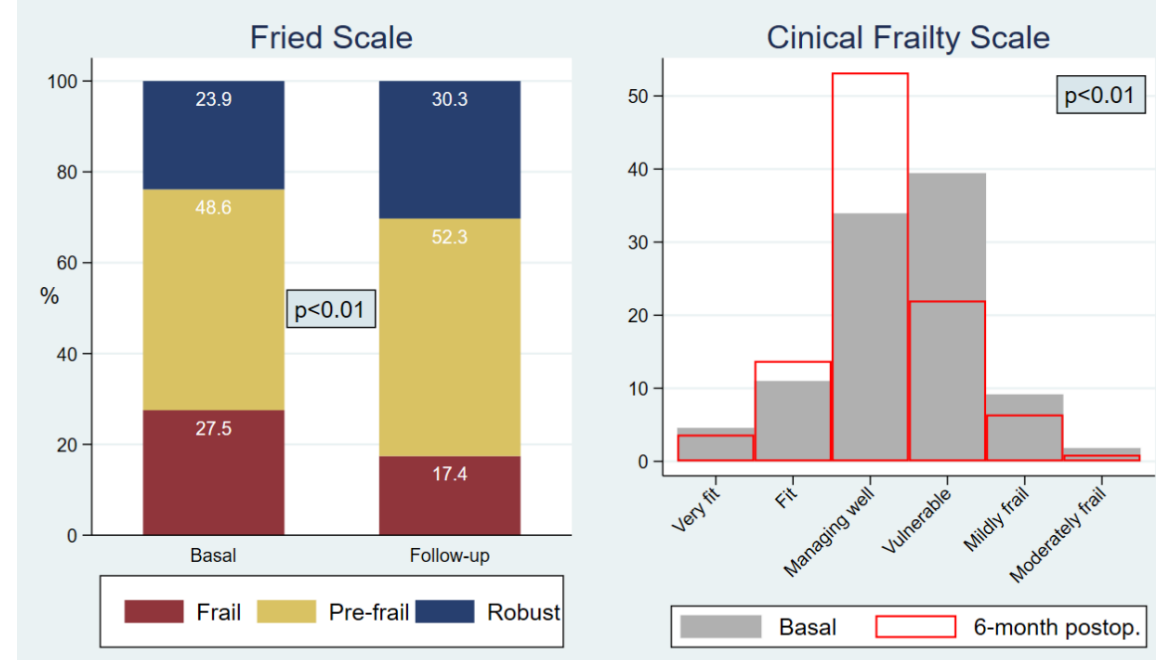

Patients who died or did not complete the follow-up period have been excluded p-values for chi-square test

Figure 3. Changes in frailty prevalence after surgery.

Changes in frailty scores after surgery

Figure 4 shows the mean changes in frailty scores for frail, pre-frail and robust patients with both scales. Negative values indicate that patients are less frail 6 months after surgery and positive values indicate a postoperative deterioration of the frailty status.

The most negative change in frailty scores occurred in the group of frail patients. Pre-frail patients showed also negative changes in frailty scores as well, although these changes were less marked that in frail patients. Conversely, robust patients experimented a slightly positive change. This linear trend in the changes of frailty scores that can be graphically appreciated, was also statistically significative $(\mathrm{p}<0.01)$ in a linear regression model. 


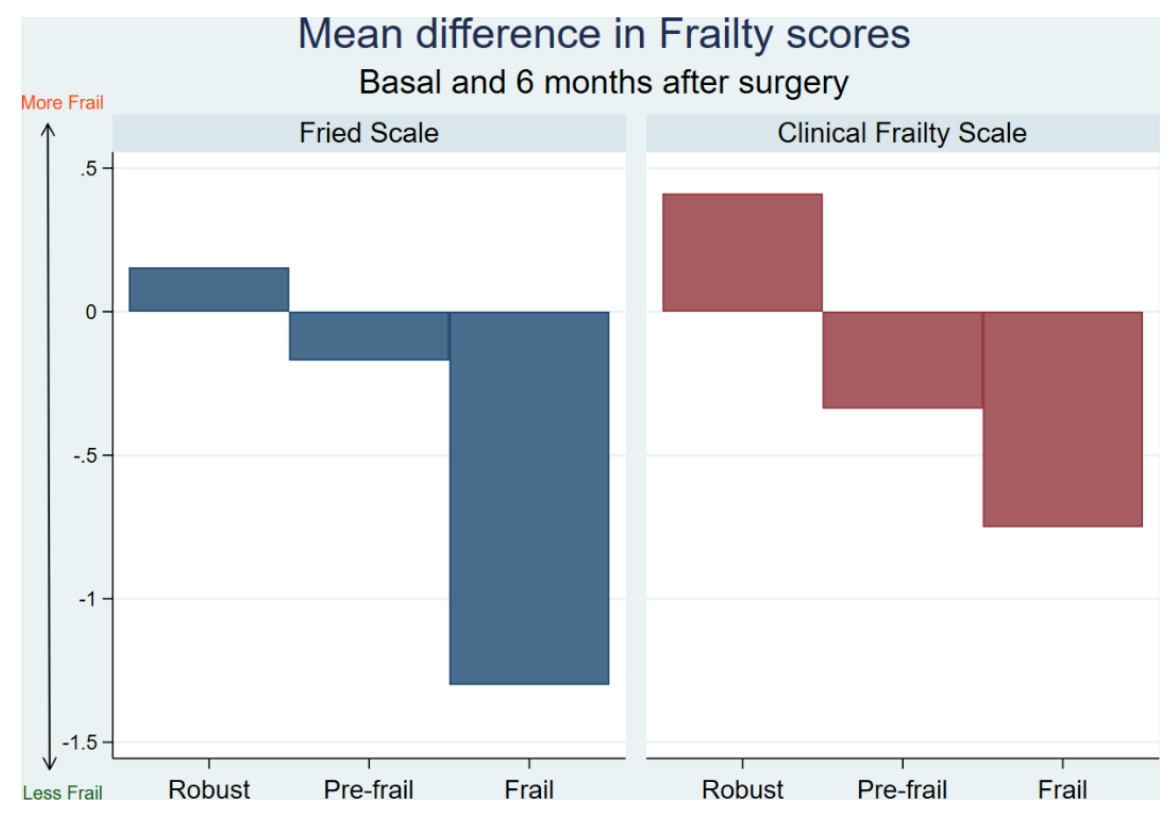

Figure 4. Mean differences in frailty scores after after surgery.

\section{Transitions between frailty status}

Changes in frailty scores are also reflected in transitions between the frailty groups between the preoperative level and the one after surgery. These changes, along with the postoperative mortality in each frailty group are shown in Table 2 .

Although Frail patients had the highest postoperative mortality, up to $50 \%$ of them improved their frailty status 6 months after surgery when frailty is assessed with the Fried scale. With the CFS, 39\% of frail patients switched to a less frail group. Most robust patients maintained their status after surgery.

Table 2. Transitions between frailty status (values are expressed as percentages).

\begin{tabular}{lllll}
\hline & & $\mathbf{6}$ Months After surgery, \% & $\mathbf{6}$ Months After surgery, \% & $\mathbf{6}$ M \\
\hline Basal Frailty Status & Basal Frailty Status & Frail & Pre-frail & Rob \\
Fried Scale & Frail (n=38) & 29 & 50 & 0 \\
& Pre-frail (n=73) & 11 & 48 & 13.7 \\
Clinical Frailty Scale & Robust (n=26) & 0 & 11.5 & 88.5 \\
& Frail (n=18) & 27.8 & 38.9 & 0 \\
& Pre-frail (n=100) & 3 & 70 & 7 \\
& Robust (n=19) & 0 & 26.3 & 63.2 \\
\hline
\end{tabular}

Changes in the components of the Fried frailty phenotype

The most significative changes in the individual domains of the frailty phenotype were found in the group of frail patients (table 3 ). Frail patients improved in all components except gait speed, which remained unchanged. The most marked change was the improvement in the feeling of exhaustion, which went from $93 \%$ to $23 \%(\mathrm{p}<0.01)$. In contrast, robust patients showed no changes, remaining practically without deficits in any of the components.

Table 3. Changes in Fried frailty scale domains after surgery. 
Changes in Fried frailty scale domains after surgery $(n=109)^{\mathrm{a}}$

Unexplained weight loss

Weak grip strength

Slow walking speed

Exhaustion

Low physical activity

Values are expressed as $n$ (\%)

(a) Patients who died or did not complete de follow-up period have been excluded. (*) p-values for Mc nemar's test for paire

\section{DISCUSSION}

The main finding of the present study is that surgery does not have a negative impact on the basal frailty status of patients referred for cardiac surgery. On the contrary, we have shown a significant improvement in the overall burden of frailty 6 months after surgery. This finding is true for both measurements that were employed to assess frailty, the Fried frailty scale and the CFS. In this way, we can confirm the dynamic and partially reversible nature of frailty in patients referred for cardiac surgery.

Changes or transitions among the ordinal levels of frailty is frequent in community-dwelling adults. As we get older, these transitions tend to occur towards a progressively greater degree of frailty. However, in frail patients who suffer a specific pathology for which there is an effective treatment, we could speculate that once this pathology has been treated effectively, the level of frailty will decrease to the extent that this pathology was contributing to it. For example, and focusing on cardiovascular medicine, the presence of heart failure secondary to a certain valve disease promotes a decrease in the level of the patient's activity and energy consumption. These decrease in the individual activity can favor the appearance of a certain degree of sarcopenia, which constitutes a central etiological element in the frailty pathophysiology. These events will have a direct negative impact on each of the items that are evaluated by the Fried Scale, that is to say: slow walking speed, muscle weakness, low physical activity, low resistance to effort and weight loss. Conversely, once the valve disease has been successfully treated and, therefore, the situation of heart failure has been resolved, it is foreseeable that the postoperative scores obtained in the different frailty scales will be improved compared to the preoperative ones.

Our results are consistent with the previous arguments. Frail and pre-frail patients showed a clear improvement in their postoperative scores on four of the five items evaluated by the Fried scale. Conversely, none of the 26 patients classified as robust with the Fried scale presented significant deterioration in the scores evaluated by this scale.

The reversibility of frailty was first shown in studies at community level during the first years of the 21st century $(27,28)$. As an example, in the study of Binder et al. (27), 152 sedentary community-dwelling people, with an average age of 83 years and with a previous screening of mild or moderate frailty, were randomized to perform various strength, balance and resistance exercises during 9 months. The individuals who performed the exercises showed a marked improvement in their previous frailty status, quantified by the modified PPT test (modified Physical Performance Test), and in their functional capacity measured through the basic and instrumental activities of daily life.

In the clinical setting and more specifically in the field of surgery, very few studies have focused on changes in the patient's frailty status after the intervention. In 2015, McAdams et al. (29), with the aim to "study the natural history of frailty after aggressive surgical intervention such as kidney transplantation", analyzed a prospective cohort of 349 patients who were assessed for frailty using the Fried scale before and after kidney transplant surgery. They showed that frailty was increased during the first postoperative month (going from 
$19.8 \%$ to $33 \%$ ), but it recovered its previous prevalence during the second month and decreased in the third month $(17.2 \%)$.

In the context of cardiac surgery, Jha et al. (20), published in 2017 a study analyzing the preoperative and postoperative frailty status of 100 patients in whom either a heart transplant was performed, or a ventricular assist device was implanted as a bridge to transplant. Similarly to our study, the authors found that most frail patients who survived the intervention showed a significant improvement in their frailty status two months after surgery.

Therefore, considering our results, we could add a decrease in the previous frailty status to the benefits provided by surgery, besides an improvement in functional capacity and quality of life. This improvement would translate into a lower risk for the occurrence of adverse health-related outcomes, such as falls, disability, need for hospitalization and dependency.

One limitation of the present study is the relatively low number de patients included, however, it has been enough to demonstrate a decrease in the global burden of frailty after surgery. Other limitation of the study is that the follow-up period is limited to 6 months. It would have been interesting to extend this period up to a year or more to see if this improvement in frailty is consolidated or, on the contrary, it tends to return to its preoperative values. As we have previously published (19), frail patients present higher postoperative mortality and morbidity rates. This could have led to a selection bias, as patients who died tend to present higher levels of frailty. However, this trend was only significative when frailty was assessed with the Fried frailty scale.

\section{BIBLIOGRAPHY}

1. Morley JE, Vellas B, van Kan GA, Anker SD, Bauer JM, Bernabei R, et al. Frailty consensus: a call to action. J Am Med Dir Assoc. 2013 Jun;14(6):392-7.

2. Fried LP, Tangen CM, Walston J, Newman AB, Hirsch C, Gottdiener J, et al. Frailty in older adults: evidence for a phenotype. J Gerontol A Biol Sci Med Sci. 2001 Mar;56(3):M146-156.

3. Mitnitski AB, Mogilner AJ, Rockwood K. Accumulation of deficits as a proxy measure of aging. ScientificWorldJournal. 2001 Aug 8;1:323-36.

4. Rockwood K, Mitnitski A. Frailty in relation to the accumulation of deficits. J Gerontol A Biol Sci Med Sci. 2007 Jul;62(7):722-7.

5. Makary MA, Segev DL, Pronovost PJ, Syin D, Bandeen-Roche K, Patel P, et al. Frailty as a predictor of surgical outcomes in older patients. J Am Coll Surg. 2010 Jun;210(6):901-8.

6. Robinson TN, Wu DS, Pointer L, Dunn CL, Cleveland JC, Moss M. Simple frailty score predicts postoperative complications across surgical specialties. Am J Surg. 2013 Oct;206(4):544-50.

7. McAdams-DeMarco MA, Law A, King E, Orandi B, Salter M, Gupta N, et al. Frailty and mortality in kidney transplant recipients. Am J Transplant Off J Am Soc Transplant Am Soc Transpl Surg. 2015 Jan;15(1):149-54.

8. Chikwe J, Adams DH. Frailty: the missing element in predicting operative mortality. Semin Thorac Cardiovasc Surg. 2010;22(2):109-10.

9. Sepehri A, Beggs T, Hassan A, Rigatto C, Shaw-Daigle C, Tangri N, et al. The impact of frailty on outcomes after cardiac surgery: a systematic review. J Thorac Cardiovasc Surg. 2014 Dec;148(6):3110-7.

10. Lee DH, Buth KJ, Martin B-J, Yip AM, Hirsch GM. Frail patients are at increased risk for mortality and prolonged institutional care after cardiac surgery. Circulation. 2010 Mar 2;121(8):973-8.

11. Afilalo J, Lauck S, Kim DH, Lefèvre T, Piazza N, Lachapelle K, et al. Frailty in Older Adults Undergoing Aortic Valve Replacement: The FRAILTY-AVR Study. J Am Coll Cardiol. 2017 Aug 8;70(6):689-700. 
12. Sündermann SH, Dademasch A, Seifert B, Rodriguez Cetina Biefer H, Emmert MY, Walther T, et al. Frailty is a predictor of short- and mid-term mortality after elective cardiac surgery independently of age. Interact Cardiovasc Thorac Surg. 2014 May;18(5):580-5.

13. Arthur HM, Daniels C, McKelvie R, Hirsh J, Rush B. Effect of a preoperative intervention on preoperative and postoperative outcomes in low-risk patients awaiting elective coronary artery bypass graft surgery. A randomized, controlled trial. Ann Intern Med. 2000 Aug 15;133(4):253-62.

14. Hulzebos EHJ, Smit Y, Helders PPJM, van Meeteren NLU. Preoperative physical therapy for elective cardiac surgery patients. Cochrane Database Syst Rev. 2012 Nov 14;11:CD010118.

15. Waite I, Deshpande R, Baghai M, Massey T, Wendler O, Greenwood S. Home-based preoperative rehabilitation (prehab) to improve physical function and reduce hospital length of stay for frail patients undergoing coronary artery bypass graft and valve surgery. J Cardiothorac Surg. 2017 Oct 26;12(1):91.

16. Stammers AN, Kehler DS, Afilalo J, Avery LJ, Bagshaw SM, Grocott HP, et al. Protocol for the PREHAB study-Pre-operative Rehabilitation for reduction of Hospitalization After coronary Bypass and valvular surgery: a randomised controlled trial. BMJ Open. 2015 Mar 9;5(3):e007250.

17. Yau DKW, Wong MKH, Wong W-T, Gin T, Underwood MJ, Joynt GM, et al. PREhabilitation for improving QUality of recovery after ELective cardiac surgery (PREQUEL) study: protocol of a randomised controlled trial. BMJ Open. 2019 14;9(5):e027974.

18. McCann M, Stamp N, Ngui A, Litton E. Cardiac Prehabilitation. J Cardiothorac Vasc Anesth. 2019 Aug;33(8):2255-65.

19. Miguelena-Hycka J, Lopez-Menendez J, Prada P-C, Rodriguez-Roda J, Martin M, Vigil-Escalera C, et al. Influence of Preoperative Frailty on Health-Related Quality of Life After Cardiac Surgery. Ann Thorac Surg. 2019;108(1):23-9.

20. Jha SR, Hannu MK, Newton PJ, Wilhelm K, Hayward CS, Jabbour A, et al. Reversibility of Frailty After Bridge-to-Transplant Ventricular Assist Device Implantation or Heart Transplantation. Transplant Direct. $2017 \mathrm{Jul} ; 3(7): \mathrm{e} 167$.

21. Knisel A, Elyasi M, Gibson G, Miller E, Fernandez H, Lima B, et al. Reversal of Frailty after LVAD Associated with Significant Reduction in Markers of Inflammation. J Heart Lung Transplant Off Publ Int Soc Heart Transplant. 2020 Apr;39(4S):S158-9.

22. Rockwood K, Song X, MacKnight C, Bergman H, Hogan DB, McDowell I, et al. A global clinical measure of fitness and frailty in elderly people. CMAJ Can Med Assoc J J Assoc Medicale Can. 2005 Aug 30;173(5):489-95.

23. Charlson ME, Pompei P, Ales KL, MacKenzie CR. A new method of classifying prognostic comorbidity in longitudinal studies: development and validation. J Chronic Dis. 1987;40(5):373-83.

24. Nashef SA, Roques F, Michel P, Gauducheau E, Lemeshow S, Salamon R. European system for cardiac operative risk evaluation (EuroSCORE). Eur J Cardio-Thorac Surg Off J Eur Assoc Cardio-Thorac Surg. 1999 Jul;16(1):9-13.

25. Nashef SAM, Roques F, Sharples LD, Nilsson J, Smith C, Goldstone AR, et al. EuroSCORE II. Eur J Cardio-Thorac Surg Off J Eur Assoc Cardio-Thorac Surg. 2012 Apr;41(4):734-44; discussion 744-745.

26. EuroQol Group. EuroQol-a new facility for the measurement of health-related quality of life. Health Policy Amst Neth. 1990 Dec;16(3):199-208.

27. Binder EF, Schechtman KB, Ehsani AA, Steger-May K, Brown M, Sinacore DR, et al. Effects of exercise training on frailty in community-dwelling older adults: results of a randomized, controlled trial. J Am Geriatr Soc. 2002 Dec;50(12):1921-8. 
28. Gill TM, Baker DI, Gottschalk M, Peduzzi PN, Allore H, Byers A. A program to prevent functional decline in physically frail, elderly persons who live at home. N Engl J Med. 2002 Oct 3;347(14):1068-74.

29. McAdams-DeMarco MA, Isaacs K, Darko L, Salter ML, Gupta N, King EA, et al. Changes in Frailty After Kidney Transplantation. J Am Geriatr Soc. 2015 Oct;63(10):2152-7.

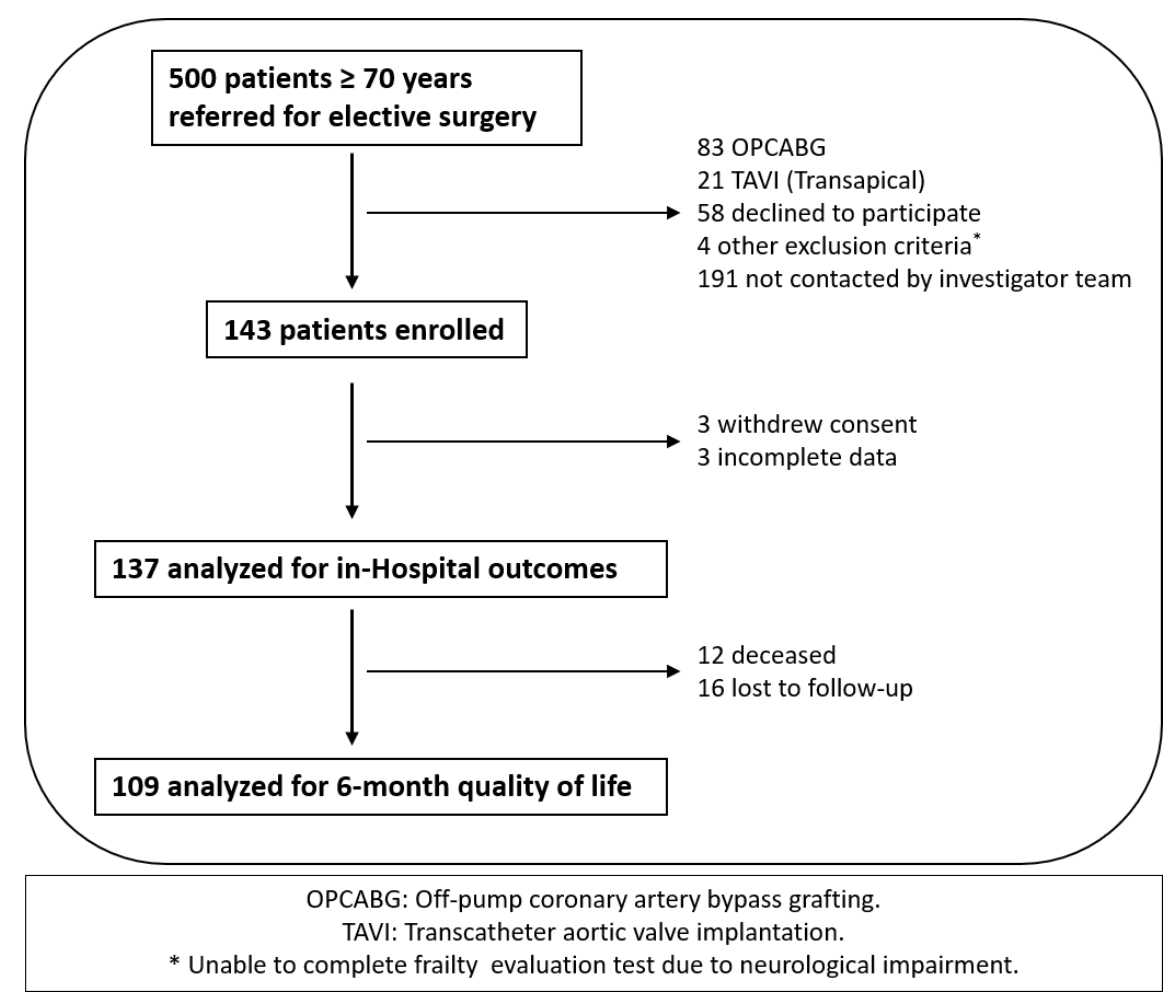




\begin{tabular}{|c|c|c|c|}
\hline & FRIED & $\mathrm{CFS}^{*}$ & \\
\hline \multicolumn{4}{|l|}{ Older age } \\
\hline \multicolumn{4}{|l|}{ Female } \\
\hline \multicolumn{4}{|r|}{ Lineal trend significance } \\
\hline \multicolumn{4}{|l|}{ High $\mathrm{BP}^{2}$} \\
\hline \multicolumn{4}{|r|}{ Lineal trend significance } \\
\hline \multicolumn{4}{|r|}{$(0,05>p<0,1)$} \\
\hline \multicolumn{4}{|l|}{ Atrial fibrillation ${ }^{3}$} \\
\hline \multicolumn{4}{|l|}{$\mathrm{COPD}^{4}$} \\
\hline \multicolumn{4}{|r|}{ * Clinical Frailty Scale } \\
\hline \multicolumn{4}{|l|}{ Charlson index } \\
\hline \multicolumn{4}{|r|}{$\begin{array}{l}\text { (1) BMI: boay mass Index ( } \mathrm{Kg} / \mathrm{mL}) \text {; (2) } \\
\text { BP: blood pressure; ; (3) Paroxystic, }\end{array}$} \\
\hline \multicolumn{4}{|r|}{ persistent or permanent atrial } \\
\hline \multicolumn{4}{|r|}{$\begin{array}{l}\text { fibrillation; (4) COPD: chronic obstructive } \\
\text { pulmonary disease ; (5) CVD: }\end{array}$} \\
\hline \multicolumn{4}{|r|}{ cerebrovascular disease; (6) NYHA: New } \\
\hline \multicolumn{4}{|r|}{ York Health Association functional class; } \\
\hline \multicolumn{4}{|r|}{ (7)Katz index of Activities of Daily Living; } \\
\hline \multicolumn{4}{|r|}{$\begin{array}{l}\text { (8) Lawton index of Instrumental } \\
\text { Activities of Daily Living; (9) Health- }\end{array}$} \\
\hline \multicolumn{4}{|r|}{ related Quality of Life index (EQ-5D); } \\
\hline \multicolumn{4}{|r|}{ (10) Health-related Quality of Life Visual } \\
\hline HRQoL (VAS) $)^{10}$ & & & Analogue Scale (EQ-5D) \\
\hline
\end{tabular}

\section{Changes in frailty prevalence}

Preoperative and 6-month postop.
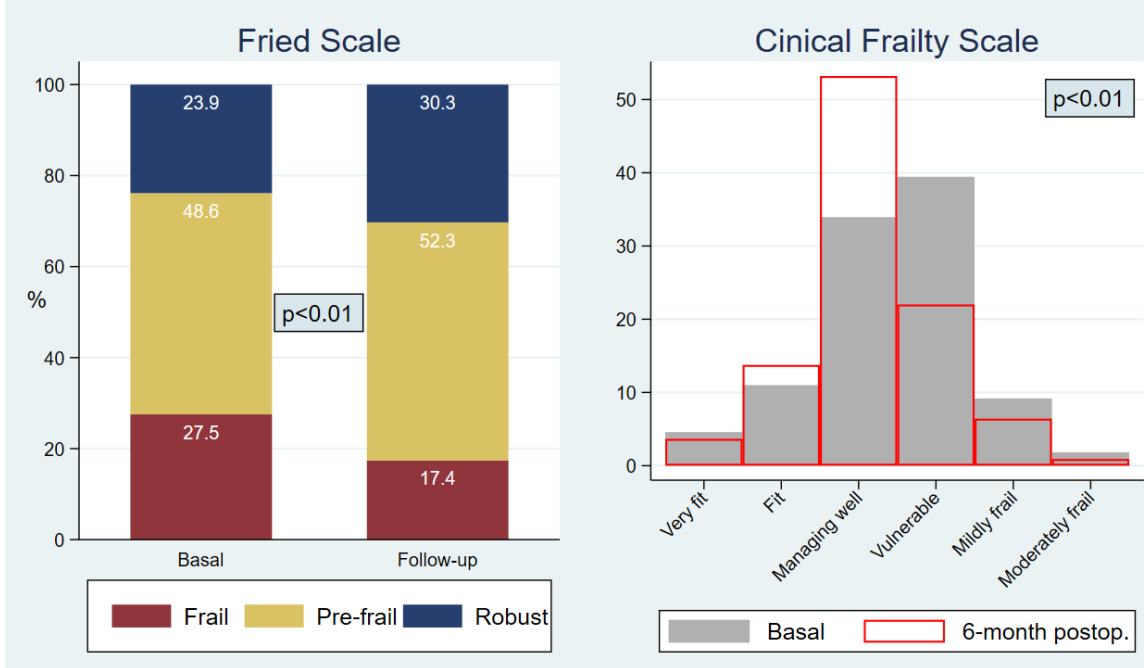

Patients who died or did not complete the follow-up period have been excluded p-values for chi-square test 


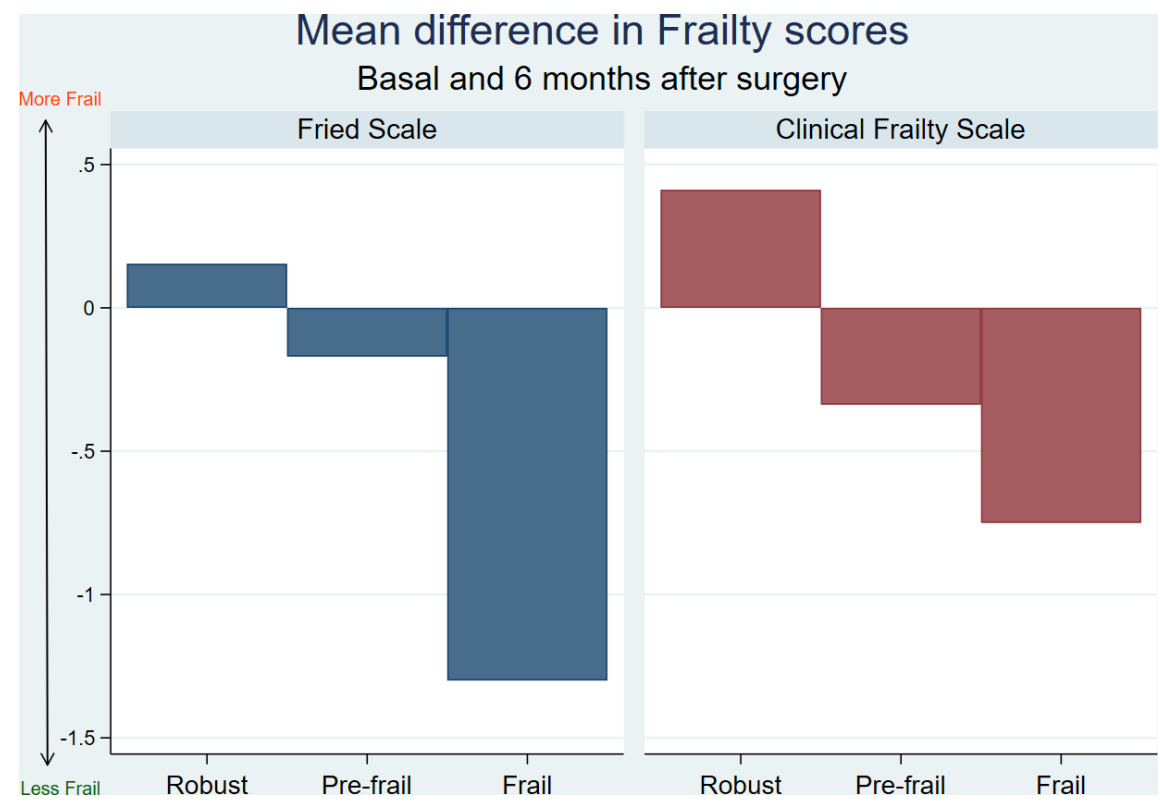

